\title{
REFLEXIONES SOBRE EL ESTATUTO JURÍDICO DE LA INFANCIA Y LA ADOLESCENCIA COLOMBIANA Y SU APLICACIÓN EN LA JUSTICIA CONSTITUCIONAL
}

\author{
Analysis on the Colombian childhood and \\ adolescence statute and it's application \\ in constitutional justice \\ ROSA ELIZABETH GUIO CAMARGO' \\ Universidad Católica de Colombia \\ reguio@ucatolica.edu.co
}

Cómo citar/Citation

Guio Camargo, R. E. (2020).

Reflexiones sobre el estatuto jurídico de la infancia y la adolescencia colombiana y su aplicación en la justicia constitucional. Anvario Iberoamericano de Justicia Constitucional, 24(1), 207-236. doi: https://doi.org/10.18042/cepc/aijc.24.07

\section{Resumen}

Hoy el derecho de infancia y adolescencia es una rama del derecho orientada al reconocimiento de los niños como sujetos activos titulares de derechos, la cual se vincula con la regulación jurídica de la familia, por lo menos en lo que tiene que ver con las relaciones entre los padres y los hijos menores de edad. Estas relaciones no tienen hoy el carácter impositivo de antaño, sino que deben desarrollarse dentro de un diálogo en el cual hay un constante balance entre las facultades legales de los padres y el ejercicio progresivo de la capacidad negociadora de los niños.

\section{Palabras clave}

Derechos de los niños; familia; Constitución; interpretación.

1 Abogada, especialista en Derecho Administrativo, magíster en Derecho y candidata al Doctorado en Derecho de la Universidad Nacional de Colombia. Docente de la Universidad Católica de Colombia y de la Universidad Nacional de Colombia. 


\section{Abstract}

Today, the right of children and adolescents is a branch of the law guided by the recognition of children as active subjects entitled to rights, which is linked to the legal regulation of the family, at least as regards relationships between parents and minor children. These relations do not have the tax character of yester year, but must be developed within a dialogue in which there is a constant balance between the legal faculties of parents and the progressive exercise of the negotiating capacity of children.

\section{Keywords}

Rights of children; family; Constitution; interpretation. 


\section{SUMARIO}

I. INTRODUCCIÓN. II. LA RELACIÓN ENTRE EL DERECHO DE FAMILIA Y EL DERECHO DE INFANCIA EN COLOMBIA: 1. Tesis de la subordinación del derecho de infancia al derecho de familia. 2. Tesis de la independencia del derecho de infancia frente al derecho de familia. 3. Tesis intermedia de la relación entre el derecho de infancia y el derecho de familia. III. LA CONSTITUCIÓN Y EL ESTADO SOCIAL DE DERECHO. REFERENCIA AL DERECHO DE INFANCIA. 1. Estado y sociedad en el Estado social de derecho. 2. La Constitución y el bloque de constitucionalidad en el Estado social de derecho. 3. La relación entre la Constitución y el derecho de la infancia en Colombia. IV. LA VINCULACIÓN DEL DERECHO DE INFANCIA CON LA CONSTITUCIÓN: ARGUMENTACIÓN JURÍDICA Y ARGUMENTACIÓN CONSTITUCIONAL. 1. Concepto y características de la argumentación jurídica. 2. Argumentación constitucional: características y alcances. 3. Mecanismos de vinculación del derecho de infancia con la Constitución: la justicia constitucional colombiana. V. CONCLUSIONES. BIBLIOGRAFía. JURISRRUDENCIA.

\section{INTRODUCCIÓN}

Dos esquemas regularon las relaciones jurídicas de los niños en vigencia de la Constitución Nacional de 1886, con la verticalidad como común denominador: de un lado los hijos de familia, cuyas relaciones estaban reguladas por el Código Civil (arts. 250 y ss.). Estos hijos estaban sometidos a la autoridad impuesta por el padre y respaldada por el Estado a través de normas de orden público; del otro, los menores, para quienes las funciones de patria potestad no existieron o fallaron en su propósito educador. Estos últimos fueron sometidos al poder estatal de funcionarios públicos mediante normas de represión y control penal, en donde se destaca la Ley 83 de 1946.

Como consecuencia de esta dualidad, el derecho de menores en Colombia - hoy derecho de infancia- se estudió por un sector de la doctrina, y durante mucho tiempo, como un capítulo del derecho de familia y, por lo tanto, de acuerdo con su lógica: relaciones paternales, parentales y legales que, dentro de un esquema de autoridad similar al del pater familias romano y en el marco privado de la institución familiar, marcaron el camino de los hijos de familia y de los menores, sin que estos tuvieran alguna posibilidad de opi- 
nar sobre los asuntos en los cuales estaban involucrados. Posteriormente, con la entrada en vigencia de la Constitución Política de 1991, la adopción de la Convención Internacional sobre los Derechos del Niño (en adelante CDN), y la relación —en el marco del bloque de constitucionalidad - entre la primera y el segundo, varió la concepción del rol de la familia y del Estado en relación con los niños para dar paso a relaciones orientadas hacia la protección integral de estos últimos, quienes son titulares activos de sus derechos y deben ser escuchados —en función de su edad y desarrollo- en los asuntos que les conciernen.

De acuerdo con los anteriores planteamientos, nos preguntamos: ¿cuál es el estatuto jurídico del derecho de infancia en Colombia a partir de la vigencia de la Constitución de 1991 y la adopción de la Convención Internacional de los Derechos del Niño?, asunto que respondemos en tres numerales: el primero presenta las tres tesis que la doctrina nacional — como elemento auxiliar para la investigación científica del derecho- ha elaborado respecto de las relaciones entre el derecho de infancia y el derecho de familia. El segundo ilustra que la tesis intermedia de las relaciones entre el derecho de infancia y el derecho de familia responde adecuadamente a la relación entre la Constitución y el derecho de infancia en el Estado social de derecho. El tercer numeral también respalda que la tesis intermedia de las relaciones entre el derecho de infancia y el derecho de familia responde de mejor manera, pues, a través de la argumentación jurídica y la argumentación constitucional, se vincula al derecho de infancia con la Constitución.

\section{LA RELACIÓN ENTRE EL DERECHO DE FAMILIA Y EL DERECHO DE INFANCIA EN COLOMBIA}

La regulación de las relaciones de familia al final del siglo XIX y comienzos del siglo XX no tuvo en cuenta a los niños como especificidad jurídica, pero sí señaló algunos de los elementos a través de los cuales se puede identificar cuál era su posición jurídica.

Así, de un lado están los hijos de familia, cuyas relaciones jurídicas, reguladas por el Código Civil que está vigente desde 1887, aunque con modificaciones sustanciales especialmente en persona y familia, tenían un carácter de imposición de los padres, sin que a los hijos les fuera posible oponerse (arts. 288 a 311); al lado de estos se encontraban los menores, quienes eran acogidos por el Estado para ser reprimidos y castigados (Ley 83 de 1946). La doctrina no se ocupó de estudiar a los hijos de familia y a los menores de manera separada a la familia, sino que su estudio se hizo en breves capítulos dentro de los textos del derecho de familia, y circunscribiéndose sólo a esta rama del 
derecho; en el caso de los menores, la doctrina se ocupó de ellos aún más esporádicamente dentro de algunos textos de derecho penal.

Posteriormente, y a instancias del trabajo de la Sociedad de las Naciones luego de la Primera Guerra Mundial, el campo jurídico de actuación de los menores y los hijos de familia se amplió, pues desde este organismo se hicieron las primeras declaraciones para reconocerlos como sujetos de derecho. Por esta razón, la doctrina colombiana consideró que la regulación jurídica de los niños era un asunto independiente del derecho de familia, que se regulaba por principios propios y tenía una lógica diferente a la de esta última rama del derecho. Surge aquí la concepción de la independencia del derecho de los niños frente al derecho de familia.

Como consecuencia tanto de la ratificación, en 1989, de la CDN, como de la aprobación de una nueva Constitución Política en 1991, la doctrina colombiana comienza a desarrollar una tesis intermedia de las relaciones entre el derecho de familia y el derecho de infancia, según la cual, si bien es cierto que las relaciones jurídicas de los niños tienen caracteres especiales, ellas no se circunscriben solo al derecho de infancia, abarcan también una importante porción del derecho de familia — pues es en este ámbito donde se desarrollan las relaciones entre los padres y los hijos- e, incluso, también tocan otras ramas, como ocurre con el derecho del consumo o el derecho laboral.

Así, las normas básicas que dan lugar a una nueva concepción jurídica de la infancia y la adolescencia son los arts. 44 y 45 de la Constitución Política, así como también la Convención de los Derechos del Niño, incorporada en la legislación nacional mediante la Ley 12 de 1991.

Las normas constitucionales mencionadas disponen:

ARTÍCULO 44. Son derechos fundamentales de los niños: la vida, la integridad física, la salud y la seguridad social, la alimentación equilibrada, su nombre y nacionalidad, tener una familia y no ser separados de ella, el cuidado y amor, la educación y la cultura, la recreación y la libre expresión de su opinión. Serán protegidos contra toda forma de abandono, violencia física o moral, secuestro, venta, abuso sexual, explotación laboral o económica y trabajos riesgosos. Gozarán también de los demás derechos consagrados en la Constitución, en las leyes y en los tratados internacionales ratificados por Colombia.

La familia, la sociedad y el Estado tienen la obligación de asistir y proteger al niño para garantizar su desarrollo armónico e integral y el ejercicio pleno de sus derechos. Cualquier persona puede exigir de la autoridad competente su cumplimiento y la sanción de los infractores.

Los derechos de los niños prevalecen sobre los derechos de los demás. 
ARTÍCULO 45. El adolescente tiene derecho a la protección y a la formación integral.

El Estado y la sociedad garantizan la participación activa de los jóvenes en los organismos públicos y privados que tengan a cargo la protección, educación y progreso de la juventud.

A su turno, la Convención de los Derechos del Niño señala, en sus arts. $1^{\circ}$ y $2^{\circ}$, lo siguiente:

ARTÍ́CULO 1. Para los efectos de la presente Convención, se entiende por niño todo ser humano menor de dieciocho años de edad, salvo que, en virtud de la ley que le sea aplicable, haya alcanzado antes la mayoría de edad.

ARTÍCULO 2. 1. Los Estados Partes respetarán los derechos enunciados en la presente Convención y asegurarán su aplicación a cada niño sujeto a su jurisdicción, sin distinción alguna, independientemente de la raza, el color, el sexo, el idioma, la religión, la opinión política o de otra índole, el origen nacional, étnico o social, la posición económica, los impedimentos físicos, el nacimiento o cualquier otra condición del niño, de sus padres o de sus representantes legales.

2. Los Estados Partes tomarán todas las medidas apropiadas para garantizar que el niño se vea protegido contra toda forma de discriminación o castigo por causa de la condición, las actividades, las opiniones expresadas o las creencias de sus padres, o sus tutores o de sus familiares.

Como puede observarse, de la lectura de estas normas se infiere un nuevo estatuto jurídico para la infancia, que pasa de estar dividida en categorías con tratamientos disímiles a ser considerada en sí misma un grupo de especial protección y atención por parte de la familia, la sociedad y el Estado; atención que debe brindarse para todos los niños, sin importar cuál sea su condición; igualmente, se les reconoce de manera expresa como sujetos titulares de derechos.

Esta consideración normativa tiene importantes implicaciones para reconocer cuál es el lugar que la doctrina le da al derecho de infancia en relación con el derecho de familia. Es así como se pueden distinguir tres enfoques o tesis, sobre esta relación: uno que considera el derecho de infancia subordinado al derecho de familia; otro, que concibe estas ramas del derecho como independientes; y un último, que las considera vinculadas a través de la Constitución. De ellas nos ocuparemos a continuación. 


\section{TESIS DE LA SUBORDINACIÓN DEL DERECHO DE INFANCIA AL DERECHO DE FAMILIA}

Quienes sostienen que el derecho de infancia está inmerso o se subordina al derecho de familia, apelan al desarrollo histórico de las relaciones familiares y consideran que el objeto del derecho de familia es regular las relaciones en su interior, y, principalmente, las de los padres con sus hijos. A esta familia se le conoce como familia en sentido estricto (Monroy, 2007: 2) o familia nuclear (Bossert y Zannoni, 2004: 6) y tiene como fin principal la reproducción (Medina, 2014: 34). Para estos autores el derecho de familia es una especialidad del derecho civil y, por lo tanto, es derecho privado regido por normas de orden público (Bossert y Zannoni, 2004: 10-11; Monroy, 2007: 34); y aun cuando algunos consideran que el derecho de infancia debiera ser independiente (Monroy, 2007: 35), finalmente sostienen que para efectos de su estudio, se entiende parte del derecho de familia (Bossert y Zannoni, 2004: 10-20, y 117; Monroy, 2007: 36; Medina, 2014: 35, 897, 899-901).

Dentro de esta corriente podemos identificar que las relaciones familiares de los niños con sus padres tienen las siguientes características: el centro de la familia es la familia nuclear, en la cual existen relaciones de autoridad sobre los hijos, enmarcadas principalmente en la patria potestad; esta autoridad es ejercida por los padres, atendiendo a sus propios intereses, pero también considerando el interés de los hijos (Bossert y Zannoni, 2004: 481-552; Monroy, 2007: 212-214; Medina, 2014: 622-623); en caso de desacuerdos, la asignación y/o distribución de las facultades derivadas de la misma es materia judicial; la falta de uno de los padres habilita al otro para ejercer exclusivamente la patria potestad, y la ausencia de ambos o el incumplimiento en las funciones implica la suspensión o privación de la patria potestad y el nombramiento de un tutor; y solo en ausencia o defecto del cumplimiento de los deberes de la familia, los niños estarán al cuidado del Estado (Bossert y Zannoni, 2004: 322 y 385; Monroy, 2007: 6-7; Medina, 2014: 679-681).

Por lo tanto, si el derecho de infancia es parte del derecho de familia y este, a su vez, es derecho civil, a las relaciones familiares entre padres e hijos puede aplicarse la teoría del negocio jurídico y de la capacidad para obligarse. De acuerdo con ello, los hijos son incapaces para obligarse por sí mismos y, por lo tanto, son sus padres quienes, en ejercicio de la patria potestad, toman las decisiones en su favor, atendiendo a su interés superior (Bossert y Zannoni, 2004: 543; Monroy, 2007: 109-134). Además, coinciden en afirmar que los derechos derivados de las relaciones familiares son derechos subjetivos familiares (Bossert y Zannoni, 2004: 9; Valencia y Ortiz, 2016: 278), y clasifican su estudio en aquellos que sirven para satisfacer intereses propios del titular del 
derecho, como la reclamación por alimentos para sí mismo, también llamados poderes-funciones, y los que se le otorgan para la protección de intereses ajenos, que es el caso de la patria potestad, que son derechos-deberes.

Aunque resulta importante que dentro de esta concepción se reconozca la relación entre la Constitución y el derecho civil — derecho de familia—, la gran dificultad de esta corriente teórica es que desconoce que en varios casos las soluciones que ofrece el derecho de familia para asuntos en los cuales están involucrados los niños suelen estar en el sentido contrario a las que, para la misma situación, plantea el derecho de infancia. Esto ocurre, por ejemplo, con la regulación sobre el matrimonio de los menores de edad y la autorización para que el niño ingrese en las fuerzas armadas.

\section{TESIS DE LA INDEPENDENCIA DEL DERECHO DE INFANCIA FRENTE AL DERECHO DE FAMILIA}

Las contradicciones entre las soluciones del derecho civil y las soluciones del derecho de infancia allanaron el camino para que un sector de la doctrina considerara que el derecho de infancia es una regulación jurídica específica y, por lo tanto, independiente del derecho de familia. Quienes sostienen esta postura no indagan por su carácter de derecho privado o derecho público, pues dan por descontado que este viejo debate está superado, y consideran que la ratificación de la CDN es el punto de partida para el surgimiento de esta nueva rama, cuya finalidad es suplir, desde el derecho, «la necesidad de arbitrar estrategias encaminadas a la atención adecuada de la niñez en aras de la formación de mejores adultos» (Liwsky, 2007: 15; Quiroz, 2009: 3; Rojas, 2008: 5).

La entrada en vigor de la CDN generó en cada uno de los países que la adoptaron el desarrollo de legislaciones específicas para regular la situación jurídica de los niños y adaptar la Convención a la normatividad interna (Torrado, 2007: 66; Daza, 2007: 78; Rojas, 2008: 5). Este proceso de adecuación no fue, en principio, afortunado: en 2004, UNICEF consideró que los únicos países que no habían adoptado legislaciones significativas en este sentido eran Argentina, Colombia, Chile y Cuba (2004: 12-15), esto pese a que Colombia expidió, en 1989, casi de manera simultánea con la ratificación de la CDN, el Código del Menor, Decreto 2737 de 1989, norma que, aunque duramente criticada, estuvo vigente hasta 2006, cuando se expidió el actual Código de la Infancia y la Adolescencia (Ley 1098 de 2006).

El mencionado Código del Menor, aun cuando para algunos fue un avance (Puyana, 2007: 313), recibió en gran medida críticas, pues dentro del universo de los niños se ocupó únicamente de los menores en situación irregular y dejó la protección de los demás, si no de lado, por lo menos 
regulada por las normas civiles y dentro del ámbito de la familia, esto es, bajo las condiciones mencionadas anteriormente. Los autores que defienden la autonomía del derecho de infancia con respecto al derecho de familia en Colombia consideran que, dentro de la legislación interna, el hito de protección de los derechos de los niños tuvo un importante avance con la expedición del Código de la Infancia y la Adolescencia en 2006, el cual enriqueció «el catálogo de derechos en favor de la niñez, desarrollando en detalle los principios contemplados en las normas de derecho internacional» (Rojas, 2008: 16-17).

Para este sector, los pilares del derecho de infancia son: el reconocimiento del interés superior del niño; el reconocimiento de que todas las personas menores de 18 años son sujetos de derecho y no solo objeto de protección (Quiroz, 2009: 3; Rojas, 2008: 17-18) y el cambio en el ejercicio de la patria potestad, la cual se orienta únicamente a la protección y cuidados indispensables de los niños. Esto tiene como consecuencia que las relaciones entre los niños y los adultos se dan «en un espacio de autonomía, dependencia y respeto, no de sumisión o limitación de los derechos» (Quiroz, 2009: 59).

\section{TESIS INTERMEDIA DE LA RELACIÓN ENTRE EL DERECHO DE INFANCIA Y EL DERECHO DE FAMILIA}

Pese a que quienes defienden la independencia del derecho de infancia con respecto al derecho de familia reconocen las relaciones entre la Constitución y la regulación jurídica de los niños, no es menos cierto que desconocen que el cambio promovido por la $\mathrm{CDN}$ no se agota con la expedición de una legislación adecuada, sino que implica «la revisión de todas las normas que afectan a la infancia siendo prácticamente la totalidad del acervo jurídico de un país» (UNICEF, 2003: 5), lo que incluye relacionarlo con el derecho de familia. Así, si una de las obligaciones de los Estados parte de la $\mathrm{CDN}$ es tomar las medidas legislativas necesarias para que los niños sean titulares activos de los derechos y se garantice su interés superior, dichas medidas no se agotan con la expedición de un Código que regule las relaciones jurídicas de los niños, sino que la totalidad de la legislación interna debe ser modificada, interpretada y/o aplicada de acuerdo con las disposiciones de la Convención.

Esta afirmación no solo demuestra que las relaciones entre el derecho de infancia y el derecho de familia no pueden entenderse como de subordinación o de autonomía del primero frente al segundo, sino que uno y otro transforman su contenido de acuerdo con los tratados internacionales de derechos humanos. Por lo tanto, si bien es muy importante que existan normas específicas para regular las relaciones jurídicas de los niños, no podemos olvidar 
que en todo el ordenamiento existen normas que resultan también aplicables a ellos, y una gran parte de estas normas están dentro del campo del derecho de familia (Kemelmajer, 2010: 384-446).

Es así como bajo la premisa de que el derecho de infancia está constituido no solo por los códigos creados para regular las relaciones jurídicas de los niños, sino también por todas aquellas normas que, de cualquier manera, los tienen como destinatarios, existe una corriente teórica intermedia. Para estos autores, la familia sigue siendo la conformada por los padres y los hijos, pero su estructura o diferentes tipologías y las relaciones entre sus miembros se ven impactadas no solo por los cambios económicos y sociales, sino también por la expedición de textos constitucionales que, en algunos casos, modificaron el sentido y alcance de la legislación civil sobre la familia, y en otros, motivaron la expedición de nuevas normas para regular situaciones familiares que, de hecho, existían y no gozaban de protección jurídica (Naciones Unidas, 1993: 7-8; Álvarez, 1988: 21-27; Valencia y Ortiz, 1995: 16-33; Kemelmajer, 2010: 93-124).

Así, la noción de autoridad ya no explica ni permite cohesionar a la familia, sino que son los conceptos de libertad, dignidad de la persona y el pluralismo social, así como también el de comunidad doméstica, los que permiten entender que las relaciones entre padres e hijos se dan hoy en un plano de coordinación, pero dentro de un marco de actuación diseñado por el legislador, cuya intervención — moderada - se justifica tanto para trazar los límites de estas relaciones como para suplir el rol de aquellas familias que no cumplieron con su cometido (Álvarez, 1988: 17; Valencia y Ortiz, 1995: 392; Kemelmajer, 2010: 35).

Si se considera entonces que la regulación del derecho de infancia desborda en el ámbito interno, este comprende también —aunque no de forma exclusiva o excluyente- aquellas normas que tienen como destinatarios a los niños, por lo que resulta imposible negar la relación entre el derecho de familia y el derecho de infancia. Y si añadimos que los criterios de interpretación y aplicación de estas normas están sometidos a la Constitución y a los tratados internacionales - y entre estos últimos la $\mathrm{CDN}$-, tenemos que aceptar que en la relación entre el derecho de infancia y el derecho de familia no prima uno sobre el otro, sino que estos se someten a la Constitución y a los tratados internacionales en favor de los niños, principalmente a la $\mathrm{CDN}$. Como consecuencia, dentro de esta corriente doctrinaria, derecho de infancia y derecho de familia se estudian simultáneamente, con los cambios que en su interpretación y aplicación imponen la Constitución y los tratados internacionales. A continuación nos ocuparemos de la relación entre la Constitución, el derecho de familia y el derecho de infancia en el Estado social de derecho. 


\section{LA CONSTITUCIÓN Y EL ESTADO SOCIAL DE DERECHO. REFERENCIA AL DERECHO DE INFANCIA}

Concebido el Estado como una abstracción social (Moncayo, 2004: 71), una estructura social (Heller, 1987: 21) o el productor del derecho que rige la sociedad (Bobbio, 1997: 169), preguntamos: ¿cuál es la relación entre el Estado y el derecho en el Estado social de derecho? En este sentido, y según lo plantea Heller, uno y otro - Estado y derecho- tienen una relación de interdependencia, ambos existen en función del hombre sujeto social y, por lo tanto, mutan por los cambios sociales. Bobbio, en contraste, considera al derecho como un elemento constitutivo del Estado, mientras que, para Moncayo, el derecho es un instrumento de dominación de los individuos. Esta relación entre el Estado y el derecho en función de la persona resulta de gran importancia para comprender el actual estatuto jurídico del derecho de infancia en Colombia, puesto que si el Estado está en función de la persona, del sujeto de derechos, la justicia constitucional logra, en varios casos, el cometido de hacer efectivos los derechos de la infancia en un contexto en el cual estos no son ya simples objetos de protección, sino que resultan ser sujetos activos titulares de sus derechos.

Aun cuando es claro que derecho no equivale a Estado ni viceversa, sí es la relación entre uno y otro en el Estado social de derecho la que permite abordar el papel que cumple el derecho dentro del Estado, el rol de la Constitución y del bloque de constitucionalidad en el Estado social de derecho, como parámetro obligatorio para la interpretación de las demás normas del ordenamiento jurídico, lo que se traduce en el derecho de infancia, en la interpretación conforme con el principio del interés superior para, de un lado, jerarquizarlas respecto de otras normas, y del otro, generar diálogos entre la Constitución, el derecho de infancia y otras ramas del derecho.

Por lo tanto, las consideraciones que se presentarán con respecto a las relaciones entre la Constitución tomada desde su valor jurídico como norma fundamental del Estado y fundamento máximo de las demás normas jurídicas sustentan la necesaria vinculación entre la Constitución y el derecho de infancia, y entre este, aquella y las demás ramas del derecho sustentan adecuadamente que el derecho de infancia, considerado desde su estudio doctrinal, no debe ser considerado ni como un apéndice del derecho de familia (tesis de la subordinación), así como tampoco se lo debe entender como totalmente desligado e independiente de esta rama del derecho (tesis de la independencia) y, por el contrario, sí se lo debe considerar como vinculado (tesis intermedia) tanto con la Constitución, de la cual derivaría su validez y la interpretación conforme a ella se convertiría en una válvula de escape y nutrición de nuevas 
formas jurídicas, como con las otras ramas del derecho, incluyendo el derecho de las relaciones familiares.

\section{ESTADO Y SOCIEDAD EN EL ESTADO SOCIAL DE DERECHO}

Teniendo en cuenta la relación entre el Estado y el derecho y reconociendo al Estado como productor del derecho, el cual objetiva las decisiones de los hombres (Heller, 1987: 199-207), abordaremos el rol del derecho en la transformación del Estado, y para justificar desde la teoría del Estado la importancia del sujeto jurídico niño, niña o adolescente.

Atendiendo a la relación jerárquica, es importante indicar el papel de la Constitución en la estructura del Estado (Heller, 1987: 267-268). Pero la Constitución no se concreta solo en una estructura normativa de superior jerarquía única, positivizada, pues, de acuerdo con Heller, «es necesario, además, que recoja elementos de la realidad, de lo social, de la cultura y el contexto en el que ella fue producida, para que así pueda ser ella eficaz» (Heller, 1987: 290; García, 1994: 126). Pasemos ahora a revisar el papel de la Constitución dentro del Estado social de derecho.

\section{LA CONSTITUCIÓN Y EL BLOQUE DE CONSTITUCIONALIDAD EN EL ESTADO SOCIAL DE DERECHO}

Entendiendo, pues, que el derecho es un elemento/producto del Estado, y que es a través de este que aquel logra dominar a la población (en una concepción capitalista), o le da sustento jurídico a las aspiraciones de los múltiples grupos sociales que conforman su población (si nos atenemos a una concepción más social), y que dentro de las normas jurídicas existe, en el Estado, primero en el Estado de derecho y luego en el Estado social de derecho, una jerarquía normativa encabezada por la Constitución; surge la necesidad de identificar cuál es el rol, el valor que esa norma máxima cumple en el Estado social de derecho.

Sobre este valor de la Constitución, señala Blanco que «la configuración del esquema de separación de poderes adoptado en las dos experiencias históricas revolucionarias liberales generadoras hacia el futuro de auténticos modelos constitucionales, las de la Revolución francesa y la Revolución Norteamericana, presenta notable relación, y en un cierto aspecto ha sido decisiva, del valor de la Constitución» (1994: 29).

Este valor es tanto político como jurídico. Por ello, sin desconocer la importancia del valor político de la Constitución, queremos ahora adentrarnos en su valor como norma jurídica, pues define el sistema de fuentes formales del derecho, y tiene una pretensión de permanencia (García de Enterría, 
1991: 49-50). Estas reflexiones también resultan aplicables al caso colombiano, debido a la influencia que tuvo el constitucionalismo europeo en general, y la Constitución española de 1978 en particular, sobre los procesos constitucionales latinoamericanos a partir de la década de los ochenta del siglo pasado (Haro, 2005: 80-84).

En materia de los derechos de los niños, el principio de la supremacía del interés superior del niño, consagrado en la parte final del art. 44 de la Constitución Política de Colombia, se constituye, de esta forma, en un elemento trascendental para la interpretación, no solo de las normas propias del derecho de infancia, sino también de aquellas que, estando en el derecho de familia, o en otras ramas del derecho, se relacionen con el ejercicio de sus derechos, de suerte que este principio no solo condiciona, en el sentido de jerarquizar la interpretación de las demás normas conforme al mismo, sino que posibilita un diálogo normativo en dos vías. De un lado, entre la Constitución, materializada en el principio del interés superior del niño y el derecho de infancia, y del otro, entre esta Constitución y las demás ramas del derecho en cuanto tengan relación, directa o indirecta, con el ejercicio de los derechos de los niños.

En el caso colombiano, la Constitución no solo está compuesta por la totalidad de los artículos de la Constitución, también comprende los tratados y convenios internacionales, dentro del concepto de bloque de constitucionalidad (Uprimny, 1992: 2; Corte Constitucional, Sentencias C-578/95, C-358/97 y C-191/98).

La Corte Constitucional colombiana considera que el bloque de constitucionalidad en materia de derechos de los niños, entre otros instrumentos internacionales, está conformado por:

La Declaración Universal de los Derechos Humanos, el Pacto Internacional de Derechos Civiles y Políticos, integrado a la legislación interna mediante la Ley 74 de 1968, la Convención de las Naciones Unidas de 1989, sobre los derechos del niño, ratificada por Colombia mediante la Ley 12 de 1992, el Convenio relativo a la protección del niño y a la cooperación en materia de adopción internacional, hecho en La Haya, el 29 de mayo de 1993 (Ley 265 de 1996), la Declaración de Ginebra sobre Derechos del Niño, la Convención Americana sobre Derechos Humanos o Pacto de San José de Costa Rica aprobado mediante la Ley 16 de 1972, el Pacto Internacional de Derechos Económicos, Sociales y Culturales —Ley 74 de 1968 - y el Protocolo adicional a la Convención Americana sobre Derechos Humanos en materia de derechos económicos, sociales y culturales, «Protocolo de San Salvador», aprobado por Colombia mediante Ley 319 de 1996 (Sentencia C-240/09). 
Tanto la consagración constitucional de los derechos de los niños como la noción de bloque de constitucionalidad son elementos que, en conjunto, permitieron estructurar la protección constitucional de la infancia bajo las siguientes premisas, establecidas por la Corte Constitucional antes de la expedición del Código de la Infancia y la Adolescencia (Sentencia C-157/07): i) sus derechos son fundamentales y prevalentes, de suerte que el ámbito normativo constitucional de protección se amplía con las normas internacionales que por disposición de la propia Carta ingresan al régimen de derechos de los niños; y ii) debido a su edad, los niños son considerados sujetos de especial protección constitucional, lo que se traduce en el deber imperativo del Estado de garantizar su bienestar.

\section{LA RELACIÓN ENTRE LA CONSTITUCIÓN Y EL DERECHO DE LA INFANCIA EN COLOMBIA}

Derivado de la comprensión de la Constitución como el texto de la misma más el bloque de constitucionalidad, los niños son hoy sujetos activos titulares de derecho, y su capacidad de ejercicio supera la señalada ordinariamente en las normas civiles, para darle aplicación a la consideración de su interés superior, $\mathrm{y}$ al derecho que les asiste para que sean escuchados y sus opiniones tenidas en cuenta en función de su edad y desarrollo, en aplicación de la denominada capacidad progresiva de ejercicio de los derechos.

Ocurre, en el caso de los derechos de los niños, que pese a que son reconocidos en el texto constitucional como fundamentales, y se establece allí también como principio para la interpretación el interés superior del niño, este principio puede considerarse, de acuerdo con la terminología propuesta por Ferreres, un concepto esencialmente controvertido, toda vez que «es claro que expresa un criterio normativo, pero personas distintas están en desacuerdo acerca del contenido específico de este criterio" y «estas expresiones controvertidas no remiten a cualquier juicio de valor, sino que señalan qué dimensión valorativa es la que hay que tomar en consideración como relevante» (1997: 25-36). Para el caso del reconocimiento de los derechos de los niños como fundamentales, es claro que este es un principio que goza de amplia aceptación y consenso en el ordenamiento jurídico colombiano, pero no ocurre lo mismo con la determinación de lo que se entiende por interés superior del niño, pues aun cuando el Comité de los Derechos del Niño realizó, en 2013, una observación general relativa a la consideración del interés superior, este último viene siendo un criterio indeterminado.

Es entonces el reconocimiento de la fundamentabilidad de los derechos de los niños, lo que Ferreres denomina como una clausula abstracta, la cual le permite al juez «extender la protección constitucional a aspectos de la libertad 
y la dignidad humanas que trascienden el ámbito protegido por disposiciones más específicas» (1997: 132). Ahora bien, ¿en qué consiste que un derecho o varios derechos - como en el caso de los niños- sean reconocidos como fundamentales? Prieto sostiene que «la interpretación formal y abstracta sobre los valores morales que venimos comentando se corresponde con la concepción liberal de los derechos humanos, así como una fundamentación de los mismos de corte iusnaturalista y racional» (1990: 23), además, dice Prieto que «no comprende sólo un programa de defensa del individuo, sino también, inescindiblemente, un modelo de comunidad política, que se conoce con el nombre de Estado de Derecho» (ibid.: 26).

Es esto, justamente, lo que ocurre con el reconocimiento de la fundamentabilidad de los derechos de los niños: no solo encarnan la pretensión humanista de que estos, los niños, sean efectivamente considerados como sujetos de derecho, sino que también, por otro lado, permiten generalizar esta condición y derivar de dicho reconocimiento aplicaciones que, solo desde el punto de vista de la ley, resultarían por lo menos problemáticas, o generan contradicciones entre normas del mismo rango, como sería el caso de considerar, solo desde el punto de vista legal, la capacidad jurídica de ejercicio de los niños prevista en el Código de la Infancia y la Adolescencia, en relación con el régimen general de capacidad para celebrar negocios jurídicos previsto en la legislación civil y mercantil: si solo consideramos estas normas, tendríamos que acudir a los criterios de especialidad y de ley posterior para darle aplicación al Código de la Infancia y la Adolescencia; y aun así, la duda surgiría en la aplicación de estas reglas al consentimiento para que el niño autorice la realización, en su cuerpo, de intervenciones quirúrgicas invasivas, pero si se toma en cuenta la norma constitucional que los señala como fundamentales, se integra a ello el bloque de constitucionalidad en materia de los derechos de los niños, surgen otros elementos a considerar, tales como la capacidad progresiva de ejercicio de los derechos por parte de los niños y, derivado de ella, el derecho que estos - los niños - tienen, para ser escuchados en todos los asuntos que les afecten y, en consecuencia, el derecho que tienen a que sus opiniones sean tenidas en cuenta en función de su edad y desarrollo.

Sobre la consagración de los derechos fundamentales, sostiene Alexy que «siempre que alguien posee un derecho fundamental, existe una norma válida de derecho fundamental que le otorga ese derecho», y vincula, así, la consideración de una norma de derecho fundamental a un criterio formal, esto es, es fundamental el derecho que se encuentre consagrado como tal en la Ley Fundamental. Ahora, una clasificación señalada como esencial para hablar de derechos fundamentales es, de acuerdo con Alexy, la distinción entre reglas y principios. Respecto de los primeros, señala que: 
[...] son normas que ordenan que algo sea realizado en la mayor medida posible, dentro de las posibilidades jurídicas y reales existentes. Por lo tanto, los principios son mandatos de optimización que están caracterizados por el hecho de que pueden ser cumplidos en diferente grado y que la medida debida de su cumplimiento no sólo depende de las posibilidades reales, sino también de las jurídicas. El ámbito de las posibilidades jurídicas es determinado por los principios y reglas opuestos. En cambio, las reglas son normas que sólo pueden ser cumplidas o no. Si una regla es válida, entonces debe hacerse exactamente lo que ella exige, ni más ni menos. Por lo tanto, las reglas contienen determinaciones en el ámbito de lo fáctica y jurídicamente posible. Esto significa que la diferencia entre reglas y principios es cualitativa y no de grado. Toda norma es, o bien una regla o un principio (1993: 86-87).

Así, en el sentido expresado por Alexy, el interés superior del niño es, en tanto principio, un mandato de optimización que debe ser cumplido en la medida en que la realidad y el derecho lo permitan; en tanto que otras normas que regulan las relaciones jurídicas de los niños, serán reglas que deberán ser acatadas si son válidas, con arreglo a criterios formales de validez.

Otra distinción que es considerada importante por Alexy es entre principios y valores. Al respecto, señala: «La diferencia entre principios y valores se reduce así a un punto. Lo que en el modelo de valores es prima facie lo mejor es, en el modelo del principio prima facie debido; y lo que en el modelo de los valores es definitivamente lo mejor es, en el modelo de los principios definitivamente debido. Así pues, los principios y los valores se diferencian sólo en virtud de su carácter deontológico y axiológico, respectivamente» (1993: 147). Ahora, si se considera como un todo, sostiene Alexy que el derecho fundamental «está compuesto por elementos con una estructura bien definida, es decir, las distintas posiciones del ciudadano y del Estado, y entre estas posiciones existen relaciones claramente determinables, las relaciones de precisión medio/fin y las relaciones de ponderación» (1993: 245).

Aquí sostenemos que, aun cuando la referencia genérica a la fundamentabilidad de los derechos de los niños en la Constitución Política pudiera prestarse para un hondo debate, la Corte Constitucional —en tanto intérprete y garante de la supremacía constitucional — ha jugado un importante papel en la interpretación y decantación de las relaciones jurídicas de los niños. Tal es el caso de la capacidad de los niños para decidir sobre la realización de intervenciones quirúrgicas en sus cuerpos, pues en este escenario los pronunciamientos de la Corte no solo sustentan la especialidad del derecho de los niños frente a las reglas negociales propias del derecho civil, sino que muestran el carácter actual de las relaciones jurídico-familiares entre los padres y los hijos menores de edad. 


\section{LA VINCULACIÓN DEL DERECHO DE INFANCIA CON LA CONSTITUCIÓN: ARGUMENTACIÓN JURÍDICA Y ARGUMENTACIÓN CONSTITUCIONAL}

La justificación jurídica, esto es, por referencia a criterios aceptados por el derecho de acuerdo con las normas que este fija para su aceptación, es el principal objeto de la argumentación jurídica, por lo que conviene ahora revisar el concepto y las características de la argumentación constitucional, entendida esta como una especie dentro del género de la argumentación. Esta argumentación constitucional cobra importancia, pues siendo hoy día la Constitución no solo la norma superior, sino de aplicación inmediata, lo que conlleva un proceso de constitucionalización del ordenamiento jurídico y, con ello, la creciente importancia de que las decisiones tomadas por el juez constitucional, en tanto intérprete de la Constitución, sean fundamentadas y controladas racional y normativamente, constituyen razones de mucho peso para considerar la importancia actual de la interpretación constitucional.

Una vez señaladas las particularidades y los retos de la interpretación constitucional en tanto espacie de interpretación jurídica, nos corresponderá examinar la forma en que la jurisdicción constitucional contribuye a la vinculación del derecho (objetivo fundamental) de los niños con la Constitución, y para esto nos serviremos de los cuatro principios estructurantes de la CDN, a saber: no discriminación; vida, supervivencia y desarrollo; interés superior del niño, y respeto por las opiniones del niño.

Bajo este entendido, no solo la tesis intermedia de las relaciones entre el derecho de familia y los derechos de los niños se sustenta adecuadamente si se tiene en cuenta la necesaria vinculación entre la Constitución y el derecho de los niños, por una parte, y entre este, la Constitución y las demás ramas del derecho, por el otro - aspecto del cual nos ocupamos en el apartado anterior-; sino que esta vinculación se puede demostrar a partir de la argumentación que la Corte Constitucional, en tanto intérprete de la Constitución y en aplicación de los principios estructurantes de la CDN, ha realizado para materializar el vínculo entre la Constitución y el derecho de infancia.

\section{CONCEPTO Y CARACTERÍSTICAS DE LA ARGUMENTACIÓN JURÍDICA}

Cuando comenzó la secularización del conocimiento surgió la argumentación jurídica, entendida como la necesidad de justificar una decisión (Tamayo y Salmorán, 2003: 54), hecho que ocurre en tres campos: la producción de normas jurídicas; la aplicación de normas jurídicas a casos concretos, y la dogmática jurídica. Esta última, a su vez, asume tres tareas: suministra criterios para la producción del derecho en diferentes instancias; presenta criterios para 
la aplicación del derecho, y ordena y sistematiza un sector del ordenamiento jurídico (Atienza, 2005: 1-2).

De lo que trata la argumentación jurídica es de encontrar normas para fundar la creación de normas o, como señala Tamayo y Salmorán, «la deducción de conclusiones a partir de principios fundamentales» (2003: 85). Alexy distingue así varios tipos de discusiones jurídicas: «[...] de la dogmática, las deliberaciones de los jueces, los debates ante los tribunales, el tratamiento de cuestiones jurídicas en los órganos legislativos, en comisiones y en comités, la discusión de cuestiones jurídicas (por ejemplo, entre estudiantes, entre abogados y entre juristas de la administración o de empresas), así como la discusión sobre problemas jurídicos en los medios de comunicación en que aparezcan argumentos jurídicos» (1993: 179). Perelman, por su parte, considera que «toda argumentación pretende la adhesión de los individuos, y, por tanto, supone la existencia de un contacto intelectual» (Hart, 1994: 125).

En conclusión, la justificación jurídica, esto es, por referencia a criterios aceptados por el derecho de acuerdo con las normas que esta fija para su aceptación, es el principal objeto de la argumentación jurídica, por lo que conviene ahora revisar las características y el alcance de la argumentación constitucional, entendida esta como una especie dentro del género de la argumentación.

\section{ARGUMENTACIÓN CONSTITUCIONAL: CARACTERÍSTICAS Y ALCANCES}

Es innegable el papel que la interpretación constitucional juega en la eficacia de los derechos fundamentales - como lo son los derechos de los niños- Tal y como se ha señalado en líneas anteriores, y siendo hoy día la Constitución no solo la norma superior, sino que puede ser aplicada inmediata y directamente, lo que conlleva un proceso de constitucionalización del ordenamiento jurídico y, con ello, la creciente importancia de que las decisiones tomadas por el juez constitucional, en tanto intérprete de la Constitución, sean fundamentadas y controladas racional y normativamente, constituyen razones de mucho peso para considerar la importancia actual de la interpretación constitucional (Uprimny, 2000: 455).

El punto de partida de Uprimny es que: «La interpretación constitucional comparte ciertos rasgos y dificultades con la práctica hermenéutica en los otros campos del derecho, pues en todos los casos se trata de una labor jurídica, en donde unos jueces, por medio de procedimientos institucionalizados, resuelven controversias, invocando para ello unos patrones normativos relativamente predeterminados y compartidos». Pero aparte de estos rasgos, también tiene particularidades: en primer lugar, dice Uprimny, 
«las características de la norma a ser interpretada (el texto constitucional), como con el lugar que ocupa el juez constitucional en el sistema político y el impacto de sus decisiones» (2000: 457).

Los textos constitucionales, que son el objeto de interpretación constitucional, tienen nociones abiertas y elásticas; son "principialistas», en el sentido de que sus normas son «formuladas en términos de principios, esto es, indican que un determinado valor debe ser protegido en la mayor medida posible, pero sin especificar las condiciones de aplicación de ese mandato, ni las consecuencias que derivan de su incumplimiento», y están atravesados por tensiones normativas permanentes y profundas, sin que la propia norma fundamental establezca jerarquías o preferencias entre esos principios (Zagrebelsky, 1995: 146).

La justicia constitucional tiene también características que la distinguen de la demás administración de justicia: en primer lugar, el juez constitucional «tiene la posibilidad de inaplicar (en los sistemas de control difuso) o anular (en aquellos de control concentrado) una ley que vulnere disposiciones constitucionales»; asunto este que les está vedado a los demás jueces; además de ello, las decisiones que se toman en el Tribunal Constitucional, por ser este no solo órgano de cierre, sino intérprete de la Constitución, carecen de recursos, y con ello, deviene este tribunal en un órgano jurídicamente infalible; y, finalmente, las decisiones de los tribunales constitucionales tienen gran impacto en la sociedad, ya sea porque tienen efecto erga omnes, o porque la doctrina que elabora debe ser respetada por otros órganos estatales (Uprimny, 2000: 459-461).

Estas características — de acuerdo con lo señalado por Uprimny- tienen un impacto muy importante en la interpretación constitucional, y esta, en consecuencia, está expuesto a interpretaciones diversas, derivadas de, por ejemplo, categorías constitucionales muy abiertas; o también de tensiones a nivel de principios si es que la mayoría de las normas constitucionales están formuladas bajo esta forma, por lo que resulta de la mayor importancia reducir la discrecionalidad de estos jueces (2000: 461-464).

En conclusión, la especial consideración, alcance y conformación de los tribunales constitucionales, de los jueces constitucionales y de la interpretación constitucional hace necesario que se establezcan controles para que esta actividad sea lo más racional posible, limitando al máximo la arbitrariedad. En este sentido, cobra importancia la afirmación de Dworkin según la cual la verdadera respuesta correcta "corresponde a la teoría que es capaz de justificar del mejor modo los materiales jurídicos vigentes» (1997: 21). 


\section{MECANISMOS DE VINCULACIÓN DEL DERECHO DE INFANCIA CON LA CONSTITUCIÓN: LA JUSTICIA CONSTITUCIONAL COLOMBIANA}

Teniendo en cuenta a Dworkin, «el derecho no es más que un dispositivo que tiene como finalidad garantizar los derechos de los individuos frente a las agresiones de la mayoría y del gobierno» (1997: 17), afirmación que cobra importancia en el punto del derecho de infancia. Así, una vez señaladas las particularidades y retos de la interpretación constitucional en tanto espacie de interpretación jurídica, nos corresponde ahora examinar la forma en que la jurisdicción constitucional contribuye a la vinculación del derecho de infancia con la Constitución, y para ello nos serviremos de los cuatro principios que el Instituto Interamericano del Niño considera como estructurantes de la Convención, y que utilizaremos como parámetro para agrupar decisiones, pues se encuentran presentes en la Constitución Política de 1991; el Comité de los Derechos del Niño los utiliza para realizar las recomendaciones a los Estados Partes de la CDN; y son aplicados por la Corte Constitucional colombiana tanto en virtud del control de constitucionalidad como en la protección de derechos fundamentales.

Estos principios, considerados como el eje de la CDN, son: la no discriminación; la vida, supervivencia y desarrollo; el interés superior del niño y el respeto por las opiniones del niño. Debemos señalar que esta no es la única clasificación de los principios que la estructuran: Cillero y Madarriaga consideran que «se estructura a partir de ciertos principios como los de interés superior del niño, no discriminación, efectividad y participación» (1999: 24). La importancia de presentar la CDN a partir de principios radica en que ellos, siendo fundamento de los derechos allí positivizados, le permiten al juez adoptar decisiones para los casos difíciles, tomándolos como base de los derechos discutidos (Dworkin, 1997: 21).

La utilización de estos principios por parte de la Corte Constitucional no obedece a la lógica de subsunción, sino que evidencia un choque con el entendimiento tradicional del juez como aplicador — no creador- del derecho y la interpretación judicial como mecanismo para aplicar normas oscuras o ambiguas; por el contrario, el uso y aplicación de estos principios son una muestra de la especial forma que toman las prácticas de argumentación a partir de la expedición de la Constitución Política de 1991. Así lo señala Diego López: «[...] el cambio, en breve, puede resumirse en lo siguiente: junto al texto expreso de la Constitución, antaño fuente indisputada de todo el derecho constitucional, hoy en día aparece el juez constitucional, a través de su jurisprudencia, como un creador consciente de subreglas constitucionales y no simplemente como un aplicador pasivo de los textos superiores» (2006: 3). Este punto cobra especial importancia en el derecho de los niños, pues 
al aplicar estos principios que estructuran la CIDN, la Corte Constitucional creó nuevas reglas de interpretación, tal y como pasa a verse.

Respecto del principio de no discriminación de los niños, el Comité de los Derechos del Niño señaló en la Observación General 5 que esta obligación exige que:

[...] los Estados identifiquen activamente a los niños y grupos de niños cuando el reconocimiento y la efectividad de sus derechos pueda exigir la adopción de medidas especiales. [...] Hay que poner de relieve que la aplicación del principio no discriminatorio de la igualdad de acceso a los derechos no significa que haya que dar un trato idéntico. En una Observación General del Comité de Derechos Humanos se ha subrayado la importancia de tomar medidas especiales para reducir o eliminar las condiciones que llevan a la discriminació».

El Instituto Interamericano del Niño establece que, en virtud de este principio, todos los niños tienen el mismo derecho a desarrollar su potencial sin importar su raza, color, género, lengua, opinión, origen, discapacidad, nacimiento u otra característica. Esta consideración del niño como un sujeto con derecho a igual consideración y respeto respecto de los adultos es, de acuerdo con el planteamiento de Dworkin, un triunfo frente a la mayoría (1997: 16). En virtud de esta prohibición de discriminación, la Corte Constitucional colombiana ordenó que factores como la edad (T-447/05) o la discapacidad de los niños (T-429/92 y T-440/04) no influyeran en el cumplimiento de la obligación estatal de brindar educación integral, y exhortó al Ministerio de Educación para que implementara programas de formación especializada a los docentes del país, con el fin de educar a los niños con déficit de atención e hiperactividad (T-255/01), modificó la regla contenida en el art. 62 del Código Civil, y señaló que tanto el padre vencido en el proceso de investigación de la paternidad, así como también el que impugna la paternidad del hijo y cuya pretensión es desestimada en el proceso, sean privados de la patria potestad sobre sus hijos (C-145/10), y declaró la inconstitucionalidad de la norma que diferenciaba la duración de la licencia de paternidad según el tiempo de afiliación al sistema de seguridad social (C-174/09).

En cuanto al principio de vida, la supervivencia y el desarrollo, el Comité de los Derechos del Niño señaló que «los niños tienen derecho a que no se les arrebate arbitrariamente la vida, así como a ser beneficiarios de las medidas económicas y sociales que les permitan sobrevivir, llegar a la edad adulta y desarrollarse en el sentido más amplio del término» (Observación General 3). Igualmente, este organismo considera que: «Las ideas de salud y desarrollo tienen un sentido más amplio que el estrictamente derivado de las disposiciones contenidas en los artículos 6 (Derecho a la vida, supervivencia y desarrollo) y 24 (Derecho a la salud) de la Convención». 
Para hacer efectivas estas garantías, la Corte Constitucional colombiana ordenó, por aplicación directa de la Constitución, el suministro de medicamentos (T-286/98, T-460/99, T-256/02, T-738/03, T-1230/03, T-399/04, T-828/04, T-186/05, T-419/05, T-740/05, T-835/05, T-976/05, T-227/06, T-344/06, T-492/07, T-511/07, T-730/07, T-324/08, T-784/08, T-1133/08, T-187/09, T-382/09, T-589/09 y T-563/10), tratamientos (T-067/94) o aparatos médicos (T-514/98 y T-044/99), realizar procedimientos quirúrgicos a niños, para que desde los puntos de vista psíquico, emocional y social, se desarrolle plenamente su personalidad (Sentencias T-068/94, T-659/03 y T-309/06), advirtió a los ciudadanos sobre la posibilidad de acudir a vías ordinarias para resolver asuntos de responsabilidad originados en fallas en la prestación del servicio médico en niños (T-576/08), y ordenó la construcción de instituciones de educación en sitios en donde la vida de los niños (T-349/93, C-225/95 y SU-256-99) no corra peligro por causa del conflicto armado.

Respecto del principio del interés superior del niño, en varias disposiciones la CDN hace referencia a este principio, que debe ser observado en los siguientes eventos: medidas que respecto de los niños tomen «las instituciones públicas o privadas de bienestar social, los tribunales, las autoridades administrativas o los órganos legislativos» cuando en virtud de decisión judicial y, como medida excepcional, deba separarse al niño de sus padres, sin perjuicio de que mantenga «relaciones personales y contacto directo con ambos padres de modo regular, salvo si ello es contrario al interés superior del niño», en cuanto al cumplimiento de las obligaciones comunes de los padres, referidas a la crianza y desarrollo del niño, cuando el niño deba ser entregado en adopción y en los casos en los que el niño deba ser sometido a sanciones por la infracción de la Ley Penal.

En los términos del Comité de los Derechos del Niño, este principio implica reconocer al niño como centro de las actuaciones que fomentan su desarrollo, tales como la educación (Observación General 1), mecanismos de lucha contra pandemias como el VIH/sida (Observación General 3), y por ello, las autoridades y particulares deben estudiar «sistemáticamente cómo los derechos y los intereses del niño se ven afectados o se verán afectados por las decisiones y las medidas que adopten; por ejemplo, una ley o una política propuestas o existentes, una medida administrativa o una decisión de los tribunales, incluyendo las que no se refieren directamente a los niños pero los afectan indirectamente» (Observación General 5).

Debido a esta consideración sobre el interés superior del niño, Cillero considera que si bien la aplicación de este principio significa darle prioridad a los derechos del niño sobre otras consideraciones culturales o cálculos de beneficio colectivo, esto también implica concebir que los derechos del niño son derechos humanos y, en esta medida, "facultades que permiten oponerse a los 
abusos del poder y superan el paternalismo que ha sido tradicional para regular los temas relativos a la infancia». En suma, afirma este autor que el interés superior del niño «puede ser concebido como un límite al paternalismo estatal y que puede orientar hacia soluciones no-autoritarias en aquellas situaciones difíciles en las que el conflicto entre derechos del niño exige utilizar una regla compleja para la construcción de una decisión que proteja efectivamente los derechos amenazados o vulnerados» (1999: 56).

La Corte Constitucional colombiana no define qué es el interés superior del niño, pero le atribuye como características: es real, en cuanto se relaciona con las particulares necesidades del niño y con sus especiales aptitudes físicas y sicológicas; es independiente del criterio arbitrario de los demás y, por tanto, su existencia y protección no dependen de la voluntad o capricho de los padres, en tanto se trata de intereses jurídicamente autónomos; es un concepto relacional, pues la garantía de su protección se predica frente a la existencia de intereses en conflicto cuyo ejercicio de ponderación debe ser guiado por la protección de los derechos del niño; y consiste en la garantía de un interés jurídico supremo, cual es el desarrollo integral y sano de la personalidad del niño (Sentencias T-408/95 y T-1051/03, Guio, 2020: 233-239).

Además, en aplicación de este principio, determinó que la acción de tutela es un mecanismo efectivo para su protección (T-1051/03), pues los niños son sujetos de derecho con protección reforzada (C-184/03); impuso deberes de actuación a las autoridades públicas (T-715/99, C-044/04, C-203/05, T-302/08, T-772/08 y C-684/09), a los particulares (T-494/05 y C-690/08) y a los padres (C-997/04); señaló que, dado que la adopción busca satisfacer el interés superior del niño (T-510/03 y T-543/04) brindándole una familia, declaró ajustada a la Constitución la exigencia legal de un término mínimo de convivencia para conceder la adopción conjunta (C-840/10) señalada en el Código de la Infancia y la Adolescencia (C-149/09 y C-468/09); y estableció que el niño tiene derecho a estar con su familia de crianza, con la que creó vínculos afectivos (T-292/04 y T-497/05). Así, podríamos decir de acuerdo con lo planteado por Diego López, que «el papel de la jurisprudencia dentro del sistema de fuentes de derecho es uno de los grandes temas de la cultura jurídica contemporánea», y su uso ha ido en aumento incluso, como señala el mismo autor, en países de tradición neorromanista (2006: 134-135)

Finalmente, en cuanto al respeto por las opiniones del niño, su contenido atraviesa otras disposiciones de la Convención, a saber: i) Derecho a expresar su opinión libremente y a que esta sea tenida en cuenta (art. 12); ii) Libertad de expresión (art. 13); iii) Libertad de pensamiento, conciencia y religión (art. 14); iv) Libertad de asociación (art. 15); y v) Acceso a una información adecuada (art. 17). 
La Observación General 12 del Comité de los Derechos del Niño está especialmente dedicada a la interpretación de este principio, en ella se señala que el respeto por las opiniones del niño es un derecho de todos los niños sin consideración a su edad, que se entiende como un proceso y no como un acontecimiento singular y aislado, y señala que aunque muchas legislaciones la han incorporado en sus legislaciones, y esto constituye un avance, proscribe aquellas prácticas que evidencian una participación simbólica y/o manipulada por los adultos.

La más importante aplicación de este principio realizada por la Corte Constitucional colombiana la constituye la línea jurisprudencial en materia de consentimiento de los niños para la realización de intervenciones quirúrgicas en su cuerpo (Sentencias T-477/95, SU-337/99, T-551/99, T-692/99, T-1390/00, T-1025/02 y T-1021/03). Así, la Corte Constitucional sostuvo que, por regla general, todo paciente debe manifestar su consentimiento para la realización de intervenciones invasivas en el propio cuerpo, este consentimiento debe ser libre, informado, cualificado, persistente y autónomo (consentimiento informado), excepcionalmente, los padres pueden manifestar su consentimiento sustituto para la realización de intervenciones médicas quirúrgicas en sus hijos menores de cinco años. Este consentimiento también debe ser libre, informado, cualificado, persistente y autónomo (consentimiento sustituto), y los niños que superan los 5 años de edad junto con sus padres pueden otorgar consentimiento asistido para la realización de intervenciones invasivas en el cuerpo del niño. Este consentimiento, además de ser libre, informado, cualificado, persistente y autónomo, debe estar siempre coadyuvado por la voluntad del niño, será precedido por la asistencia científica de un equipo interdisciplinario, el cual debe llegar a un consenso médico sobre la mejor alternativa que consulte el principio de beneficencia, y, finalmente, para otorgar este consentimiento, los padres y el niño deben adecuarse a las recomendaciones médicas.

Como conclusión de este apartado, podemos señalar que desde 1992 y hasta la fecha, la Corte Constitucional, en calidad de órgano que encabeza la jurisdicción constitucional y entidad encargada de guardar la supremacía de la Constitución y de garantizar la efectividad de los derechos de las personas, ha sido determinante en cuanto a la aplicación directa de los principios constitucionales de: i) no discriminación; ii) vida, supervivencia y desarrollo; iii) interés superior del niño; y iv) respeto por sus opiniones, a las relaciones jurídicas de los niños; principios que, por demás, salvaguardan el principio democrático y se constituyen en elementos que el juez debe tomar en cuenta para crear o descubrir nuevos derechos al decidir en casos difíciles. 


\section{CONCLUSIONES}

Hoy coexisten las tres tesis que describen cómo es la relación entre el derecho de familia y el derecho de infancia en Colombia; cada una de ellas tiene tanto virtudes como dificultades:

El principal aporte de la tesis de la subordinación del derecho de infancia al derecho de familia es que este sector de la doctrina reconoce la relación entre la Constitución y el derecho civil — derecho de familia—; pero su gran dificultad radica en desconocer que, en varios casos, las soluciones que ofrece el derecho de familia para asuntos en los cuales están involucrados los niños suelen estar en el sentido contrario a las que, para la misma situación, plantea el derecho de infancia.

En cuanto a la tesis de la independencia del derecho de infancia respecto del derecho de familia, su principal aporte es que reconoce las relaciones entre la Constitución y la regulación jurídica de los niños, pero también es cierto que su dificultad radica en que desconoce que el derecho de infancia no es solo una regulación específica y especial para las personas menores de edad, sino que ella debe permear todo el sistema jurídico de un país, lo que incluye, por supuesto, relacionar el derecho de infancia con el derecho de familia.

Finalmente, la tesis intermedia cuyo aporte es relacionar tanto el derecho de infancia con el derecho de familia, y a estos, a su vez, con la Constitución y con los tratados internacionales sobre derechos humanos es la que describe de mejor manera cómo debe asumir la doctrina colombiana las relaciones entre el derecho de familia y el derecho de infancia, pues no solo reconoce la relación entre la Constitución, el derecho de familia y el derecho de infancia en el Estado social de derecho, sino que, a través de la argumentación jurídica y la argumentación constitucional, vincula al derecho de infancia con la Constitución, lo que permite dinamizarlo y hacerlo efectivo.

Siendo el derecho un producto del Estado, y otorgándole el derecho al Estado no solo su estructura formal, sino todo un andamiaje de normas y principios que deben ser aplicados directamente — los primeros-, y satisfechos en la medida de las posibilidades reales y jurídicas — los segundos-, se descarta que el derecho de infancia dependa de la regulación de las relaciones familiares, así como también son erradas las concepciones doctrinarias que lo consideran como absolutamente independiente del derecho de familia; por dos razones: i) toda la validez jurídica de las normas de rango legal deriva de la Constitución; y ii), porque la Constitución, integrada, entre otras prescripciones jurídicas, por reglas y principios, impone que estos últimos —en tanto mandatos de optimización - sean satisfechos en la medida de las posibilidades reales y jurídicas, lo que significa, en el caso concreto del derecho objetivo - fundamental de los niños, que el principio del interés superior del 
niño no solo permee, sino que rebase por completo el ámbito del derecho de familia y sea utilizado en la aplicación de otras normas a la regulación de las relaciones jurídicas de los niños.

Para el caso del derecho de infancia, la Corte Constitucional utiliza criterios de argumentación de sus decisiones basadas en las propias normas constitucionales, lo cual no solo amplía el espectro de la fundamentabilidad de los derechos de los niños, sino que también demuestra que la tesis intermedia de las relaciones entre el derecho de infancia y el derecho de familia es la más adecuada para describir el estatus jurídico doctrinal de esta relación, porque reconoce que la argumentación jurídica, y su especie, argumentación constitucional, muestran la vinculación existente entre, de un lado, la Constitución y el derecho de los niños, y del otro, la Constitución, el derecho de familia y otras ramas del derecho.

\section{Bibliografía}

Alexy, R. (1989). Teoría de la argumentación jurídica. Madrid: Centro de Estudios Constitucionales.

- (1993). Teoría de los derechos fundamentales. Madrid: Centro de Estudios Constitucionales.

Álvarez, J. (1988). Curso de derecho de familia. Patria potestad, tutela y Alimentos. Madrid: Civitas.

Atienza, M. (2005). Las Razones del Derecho. Teoría de la Argumentación Jurídica. México: Instituto de Investigaciones Jurídicas.

Blanco, R. (1994). El valor de la Constitución. Madrid: Alianza.

Bobbio, N. (1997). Estado, Gobierno y Sociedad por una teoría general de la politica. Bogotá: Fondo de Cultura Económica.

Bossert, G. y Zannoni, E. (2004). Manual de derecho de familia. Buenos Aires: Astrea. Cillero, M. (1999). El interés superior del niño en el marco de la Convención Internacional sobre los Derechos del Niño. Justicia y derechos del niño, 1. Disponible en: http://www.jurisprudenciainfancia.udp.cl/wp/wp-content/uploads/2009/08/ miguel-cillero-brunol.pdf.

Cillero, M. y Madarriaga, H. (1999). Infancia, derecho y justicia situación de los derechos del niño en América Latina y la reforma legislativa en la década de los noventa. Santiago de Chile: UNICEF- Departamento de Sociología, Facultad de Ciencias Sociales, Universidad de Chile.

Daza, R. (2007). Panorama de la violencia contra los niños en América Latina. En E. Durán y Ma. C. Torrado (eds.). Derechos de los niños y las niñas. Debates, realidades y perspectivas. Bogotá: Siglo del Hombre Editores. 
Durán, E. (2007) Los derechos de los niños y las niñas: marco general y puntos de debate. En E. Durán y Ma. C. Torrado (eds.). Derechos de los niños y las niñas. Debates, realidades y Perspectivas. Bogotá: Siglo del Hombre Editores.

Dworkin, R. (1997). Los Derechos en serio. Barcelona: Ariel.

Ferreres, V. (1997). Justicia constitucional y democracia. Madrid: Centro de Estudios Políticos y Constitucionales.

García, M. (1994). Las transformaciones del Estado contemporáneo. Madrid: Alianza Editorial.

García de Enterría, E. (1991). La Constitución como norma y el tribunal constitucional. Madrid: Civitas.

Guio, R. (2020). El interés superior del niño. En C. Cardozo (ed.). Principios generales del derecho privado. Bogotá: Universidad Católica de Colombia.

Haro, R. (2005). Algunas reflexiones sobre la influencia de la Constitución Española de 1978 en el constitucionalismo latinoamericano (en conmemoración del 25\% aniversario: 1978-2003). Anuario de Derecho Constitucional Latinoamericano, 1, 57-86 Disponible en: http://www.juridicas.unam.mx/publica/librev/rev/ dconstla/cont $/ 2005.1 / \mathrm{pr} / \mathrm{pr} 5 . \mathrm{pdf}$.

- (1994). The concept of law. Buenos Aires: Abeledo.

Heller, H. (1987). Teoría del Estado. México: Fondo de Cultura Económica.

Kemelmajer, A. (2010). El nuevo derecho de familia: visión doctrinal y jurisprudencial. Bogotá: Pontificia Universidad Javeriana.

Liwski, N. (2007). Realidades y perspectivas de los derechos de los niños y las niñas en América Latina. En E. Durán y Ma . C. Torrado (eds.). Derechos de los niños y las niñas. Debates, realidades y Perspectivas. Bogotá: Siglo del Hombre Editores.

López, D. (2006). El derecho de los jueces. Bogotá: Legis.

Medina, J. (2014). Derecho civil: derecho de familia. Bogotá, Universidad del Rosario. Moncayo, V. (2004). El leviatán derrotado. Bogotá: Grupo Editorial Norma.

Monroy, M. (2007). Derecho de familia y de menores. Bogotá: Librería Ediciones del Profesional.

Naciones Unidas (1993). El cambio social en Colombia y sus repercusiones en la familia. Santiago de Chile: Comisión Económica para América Latina y el Caribe. Disponible en: http://repositorio.cepal.org/bitstream/handle/11362/9353/ S9320101_es.pdf?sequence=1.

Naciones Unidas. Comité de los Derechos del Niño (2003). Observación General No. 5. Medidas generales de aplicación de la Convención sobre los Derechos del Niño artículos 4 y 42 y párrafo 6 del artículo 44.

Perelman, Ch. (1988). Tratado de argumentación. Madrid: Civitas.

Prieto, Luis (1990). Estudios sobre derechos fundamentales. Madrid: Debate.

Puyana, Y. (2007). Los cambios en la paternidad y la maternidad y las formas tradicionales de castigo. En E. Durán y Ma . C. Torrado (eds.). Derechos de los niños y las niñas. Debates, realidades y Perspectivas (pp. 301-314). Bogotá: Siglo del Hombre Editores.

Quiroz, A. (2009). Manual derecho de infancia y adolescencia (aspectos sustanciales y procesales). Bogotá: Librería Ediciones del Profesional. 
Rojas, M. (2008). Restablecimiento de derechos de la infancia. Bogotá: Editorial Universidad de los Andes.

Tamayo y Salmorán, R. (2003). Razonamiento y argumentación jurídica. El paradigma de la racionalidad y la ciencia del Derecho. México: Universidad Autónoma de México.

Torrado, Ma . C. (2007). La Convención de los derechos de los niños como marco para pensar la política social. En: E. Durán y M. C. Torrado (eds.). Derechos de los niños y las niñas. Debates, realidades y Perspectivas (pp. 65-75). Bogotá: Siglo del Hombre Editores.

UNICEF (2003). Justicia penal juvenil: buenas prácticas para América Latina. UNICEF: Oficina Regional para América Latina y el Caribe. Disponible en http:// www.unicef.org/lac/justicialjuvenil.pdf.

- (2004). La Convención sobre los Derechos del Niño quince años después: América Latina. UNICEF: Oficina Regional para América Latina y el Caribe. Disponible en http://www.unicef.org/lac/cdn_15_anos_Espfull(2).pdf.

Uprimny, R. (1992). El dilema de la interpretación constitucional En F. Morón Díaz et al. Jurisdicción constitucional de Colombia. La corte constitucional 1992-2000. Realidades y perspectivas (vol. 2000, 455-464). Bogotá: Konrad Adenauer y Escuela Judicial Rodrigo Lara Bonilla.

Valencia, A. y Ortiz, Á. (2016). Derecho civil. Parte general y personas. Bogotá: Temis.

- (1995). Derecho civil. Derecho de Familia. Bogotá: Temis.

Zagrebelsky, G. (1995). El derecho dúctil. Madrid: Trotta.

\section{Jurisprudencia}

Colombia. Corte Constitucional. Sentencia T-429 de 1992.

Colombia. Corte Constitucional. Sentencia T-349 de 1993

Colombia. Corte Constitucional. Sentencia T-067 de 1994.

Colombia. Corte Constitucional. Sentencia T-068 de 1994.

Colombia. Corte Constitucional. Sentencia C-225 de 1995.

Colombia. Corte Constitucional. Sentencia T-408 de 1995.

Colombia. Corte Constitucional. Sentencia T-477 de 1995.

Colombia. Corte Constitucional. Sentencia C-578 de 1995.

Colombia. Corte Constitucional. Sentencia C-191 de 1998.

Colombia. Corte Constitucional. Sentencia T-286 de 1998

Colombia. Corte Constitucional. Sentencia T-514 de 1998.

Colombia. Corte Constitucional. Sentencia T-044 de 1999.

Colombia. Corte Constitucional. Sentencia SU-256 de 1999.

Colombia. Corte Constitucional. Sentencia SU-337 de 1999.

Colombia. Corte Constitucional. Sentencia T-460 de 1999.

Colombia. Corte Constitucional. Sentencia T-551 de 1999.

Colombia. Corte Constitucional. Sentencia T-692 de 1999.

Colombia. Corte Constitucional. Sentencia T-715 de 1999. 
Colombia. Corte Constitucional. Sentencia C-240 de 2000.

Colombia. Corte Constitucional. Sentencia T-1390 de 2000.

Colombia. Corte Constitucional. Sentencia T-255 de 2001.

Colombia. Corte Constitucional. Sentencia T-256 de 2002.

Colombia. Corte Constitucional. Sentencia T-1025 de 2002.

Colombia. Corte Constitucional. Sentencia T-510 de 2003.

Colombia. Corte Constitucional. Sentencia T-1021 de 2003.

Colombia. Corte Constitucional. Sentencia T-659 de 2003.

Colombia. Corte Constitucional. Sentencia T-738 de 2003.

Colombia. Corte Constitucional. Sentencia T-1051 de 2003.

Colombia. Corte Constitucional. Sentencia T-1230 de 2003.

Colombia. Corte Constitucional. Sentencia C-044 de 2004.

Colombia. Corte Constitucional. Sentencia T-292 de 2004.

Colombia. Corte Constitucional. Sentencia T-399 de 2004.

Colombia. Corte Constitucional. Sentencia T-440 de 2004.

Colombia. Corte Constitucional. Sentencia T-543 de 2004.

Colombia. Corte Constitucional. Sentencia T-828 de 2004.

Colombia. Corte Constitucional. Sentencia C-997 de 2004.

Colombia. Corte Constitucional. Sentencia T-186 de 2005.

Colombia. Corte Constitucional. Sentencia C-203 de 2005.

Colombia. Corte Constitucional. Sentencia T-419 de 2005.

Colombia. Corte Constitucional. Sentencia T-447 de 2005.

Colombia. Corte Constitucional. Sentencia T-494 de 2005.

Colombia. Corte Constitucional. Sentencia T-497 de 2005.

Colombia. Corte Constitucional. Sentencia T-740 de 2005.

Colombia. Corte Constitucional. Sentencia T-835 de 2005.

Colombia. Corte Constitucional. Sentencia T-976 de 2005.

Colombia. Corte Constitucional. Sentencia T-227 de 2006.

Colombia. Corte Constitucional. Sentencia T-307 de 2006.

Colombia. Corte Constitucional. Sentencia T-344 de 2006.

Colombia. Corte Constitucional. Sentencia T-599 de 2006.

Colombia. Corte Constitucional. Sentencia C-157 de 2007.

Colombia. Corte Constitucional. Sentencia T-492 de 2007.

Colombia. Corte Constitucional. Sentencia T-511 de 2007.

Colombia. Corte Constitucional. Sentencia T-730 de 2007.

Colombia. Corte Constitucional. Sentencia T-302 de 2008.

Colombia. Corte Constitucional. Sentencia T-324 de 2008.

Colombia. Corte Constitucional. Sentencia T-576 de 2008.

Colombia. Corte Constitucional. Sentencia C-690 de 2008.

Colombia. Corte Constitucional. Sentencia T-772 de 2008.

Colombia. Corte Constitucional. Sentencia T-784 de 2008.

Colombia. Corte Constitucional. Sentencia T-1133 de 2008.

Colombia. Corte Constitucional. Sentencia C-149 de 2009.

Colombia. Corte Constitucional. Sentencia C-174 de 2009. 
Colombia. Corte Constitucional. Sentencia T-187 de 2009.

Colombia. Corte Constitucional. Sentencia T-382 de 2009.

Colombia. Corte Constitucional. Sentencia C-468 de 2009.

Colombia. Corte Constitucional. Sentencia T-589 de 2009.

Colombia. Corte Constitucional. Sentencia C-684 de 2009.

Colombia. Corte Constitucional. Sentencia C-145 de 2010.

Colombia. Corte Constitucional. Sentencia T-563 de 2010.

Colombia. Corte Constitucional. Sentencia T-572 de 2010.

Colombia. Corte Constitucional. Sentencia C-840 de 2010. 